Article

\title{
The Structural Integrity and Fracture Behaviour of Teeth Restored with PEEK and Lithium-Disilicate Glass Ceramic Crowns
}

\author{
Sami Aldhuwayhi ${ }^{1}\left(\mathbb{D}\right.$, Muhammad Syafiq Alauddin ${ }^{2, *}$ and Nicolas Martin ${ }^{3, *(D)}$ \\ 1 Department of Prosthodontics, College of Dentistry, Majmaah University, Al-Majmaah 11952, Saudi Arabia; \\ s.aladdowihi@mu.edu.sa \\ 2 Department of Conservative Dentistry \& Prosthodontics, Faculty of Dentistry, USIM, \\ Kuala Lumpur 55100, Malaysia \\ 3 Academic Unit of Restorative Dentistry, University of Sheffield, Sheffield S10 2TA, UK \\ * Correspondence: syafiq.alauddin@usim.edu.my (M.S.A.); n.martin@sheffield.ac.uk (N.M.)
}

Citation: Aldhuwayhi, S.; Alauddin, M.S.; Martin, N. The Structural Integrity and Fracture Behaviour of Teeth Restored with PEEK and Lithium-Disilicate Glass Ceramic Crowns. Polymers 2022, 14, 1001. https://doi.org/10.3390/ polym14051001

Academic Editor: Filippo Berto

Received: 13 December 2021

Accepted: 26 January 2022

Published: 1 March 2022

Publisher's Note: MDPI stays neutral with regard to jurisdictional claims in published maps and institutional affiliations.

Copyright: (C) 2022 by the authors. Licensee MDPI, Basel, Switzerland. This article is an open access article distributed under the terms and conditions of the Creative Commons Attribution (CC BY) license (https:// creativecommons.org/licenses/by/ $4.0 /)$.

\begin{abstract}
Polyetheretherketone (PEEK) is a unique polymer material which has recently been introduced to dentistry. This study aimed to assess the structural integrity of PEEK as a posterior tooth crown and compared it with ceramic-based material. A total of 31 monolithic CAD-CAM PEEK (Juvora $^{\mathrm{TM}}$, Strumann, Andover, MA, USA) crowns and 31 lithium disilicate (IPS e.max ${ }^{\circledR}$ CAD, Voclar Vivadent AG, Liechtenstein) crowns were created and cemented on dentin-like teeth (AlphaDie ${ }^{\circledR} \mathrm{MF}$, Schütz Dental GmbH, Rosbach, Germany) in a precise procedure mimicking the physical and mechanical properties of natural teeth and periodontal ligaments. A static compressive strength test using a universal testing machine and a dynamic fatigue test using a chewing simulator machine were used until crown failure to assess the fracture behaviour by mode of fracture (fractographic analysis) and 3D digital subtraction analysis. The results showed that PEEK has a greater fracture resistance than IPS e.max ${ }^{\circledR}$ CAD by $2060 \mathrm{~N}$ to $703 \mathrm{~N}$. Additionally, in fatigue limit, IPS e.max ${ }^{\circledR} \mathrm{CAD}$ showed a constant failure under $2.0 \mathrm{Kg}(=320 \mathrm{~N})$ before 5000 chewing cycles while PEEK survived at a significantly higher load $>11 \mathrm{Kg}(930 \mathrm{~N})$. Furthermore, PEEK showed a continued survival at $>1,250,000$ cycles while the mean fatigue life of IPS e.max ${ }^{\circledR}$ CAD was around 133,470 cycles. PEEK illustrated a significantly less catastrophic failure mode with some plastic deformation at the fractographic stereomicroscope and in the 3D digital subtraction analysis. Using PEEK for crowns looks very promising, however, further clinical studies are required to assure this study's results.
\end{abstract}

Keywords: PEEK; IPS e.max ${ }^{\circledR}$ CAD; structural integrity; fatigue life and limit; dental crown

\section{Introduction}

A wide range of materials can fabricate full-coverage crowns for the restoration of structurally compromised teeth. Metals, metal ceramics and all ceramic crowns are the most prevalent materials with good survival rates and clinical properties (mechanical and aesthetic) derived from the inherent characteristics of the material [1-7]. To date, polymerbased materials have been characterised by a low fracture strength and wear rate which has made them unsuitable for this restorative purpose. A new group of such materials have been developed in recent years from the generic group of polyaryletherketone (PAEK). Within this group, the material polyetheretherketone (PEEK), a semicrystallize thermosoftening polymer, has the potential for a framework for fixed and removable prostheses by virtue of its biocompatibility and desirable physical and mechanical properties [8,9]. PEEK materials have rigidity comparable to bone fixation plates for fractured bones, orthopaedic implants, joint arthroplasty, and vertebral cages $[10,11]$. In dentistry, PEEK has various applications due to its good biological, mechanical, aesthetic, and handling properties with excellent results in comparison to other conventional materials [12-21]. 
The use of PEEK for extra-coronal restorations with a laminated outer RBC is a new application that requires testing and validation. In addition to assessing the material's inherent properties per se, it is equally important to determine its structural integrity as part of a tooth-restoration complex. This can be achieved through mechanical stress tests in the form of monotonic (static test-fracture test) or cyclic (dynamic-fatigue cyclic loading) tests $[22,23]$. Fatigue can be defined as the strength degradation and weakening of a material caused by repeatedly applying loads which ultimately could cause material failure [2]. Fatigue stress due to repetitive occlusal load has been proven to be the most common reason for clinical dental prosthesis failure [24,25]. The fatigue behaviour of any material structure is achieved by measuring the fatigue limit and the fatigue life of the test specimen. Several studies have used both concepts $[15,17,18,21,24,26]$. Fatigue limit is the maximum amount of stress that the structure can survive for a predetermined number of loading cycles. The most suitable method to be evaluated used the staircase technique and the average number of samples used were between 10 and $20[15,17,18]$. One the other hand, fatigue life is the maximum number of cycles that the body can withstand without failure for the given amount of stress. Survival of more than 1,200,000 chewing cycles (representing five years of clinical service) is considered clinically acceptable $[19,20]$. The number of samples needed for fatigue life test varies between the studies depending on testing procedure, the higher limit of fatigue life, the machine, and material used etc. Variable fatigue testing and chewing simulating machines have been used in fatigue test studies $[13,15,18,19,24,27,28]$. Comparing the outcome data between these different machines is impossible as they depend entirely on the testing machine. Notwithstanding this in vitro simulation, mechanical setup allows for performance comparison of materials and/or restorative systems that are subject to the same loads. One of these fatigue testing machines has been constructed by Mair et al. and validated in several studies [15,16,29]. This mechanical machine consists of five independent stations with the specimens submerged in a controlled temperature water bath. Test specimens are subjected to the impact of indenters of a specific form and shape (representing an antagonist molar cusp).

A challenge with in vitro testing of restorative systems arises in the choice of dental substrate. Natural teeth are more realistic and represent the actual crown substructure in the mouth. Their use in these studies is limited by their availability and the significant anatomic, histological, and structural variability. Polymer replica teeth with matched elastic modulus close to dentine provide a standardised substrate for the tests within and across groups $[20,21,30-32]$.

This study aims to undertake a comparative assessment of the crown-tooth complex's structural integrity and fracture behaviour when restored with either PEEK or lithium disilicate glass ceramic crowns that are adhesively cemented to premolar polymer typodonts. The results will help predict the clinical performance, durability, and failure mode of machined monolithic PEEK crown on posterior teeth.

\section{Material and Method}

A lack of data from previous literature that directly compared lithium disilicate glass ceramic IPS e.max ${ }^{\circledR}$ CAD (control group) to machined PEEK crown (test group) made it difficult to develop a power calculation. The test was repeated in a sequential manner until a statistical significance of $<0.05(p<0.05)$ was achieved. Due to the identical and carefully controlled samples, the approach in this study was to undertake an initial investigation using 10 samples of each group for static testing and 30 samples of each group were prepared for both dynamic tests following the chewing simulator machine designer's recommendations.

\subsection{Tooth Preparation}

A total of two identical typodont upper right second premolars (AG-3, Frasaco, Frasaco GmBh, Tettnang, Germany) were prepared to receive a full coverage Monolithic PEEK crown (Juvora ${ }^{\mathrm{TM}}$ ) and a monolithic lithium disilicate (IPS e.max ${ }^{\circledR}$ CAD, Ivoclar Vivadent, 
Schaan, Liechtenstein) crown in accordance with the required preparation guidelines (Table 1). Consistency of preparations was achieved through the use of a parallelometer to hold a dental turbine and a bur at the required taper angulation.

Table 1. The preparation guidelines as per the manufacturer's instructions of IPS e.max CAD and PEEK by Juvora ${ }^{\mathrm{TM}}$.

\begin{tabular}{ccc}
\hline Groups & $\begin{array}{c}\text { Monolithic Lithium Disilicate IPS } \\
\text { e.max CAD }\end{array}$ & PEEK by Juvora ${ }^{\mathrm{TM}}$ \\
\hline Occlusal reduction & $1.5 \mathrm{~mm}$ & $1.5 \mathrm{~mm}-2.0 \mathrm{~mm}$ \\
\hline Axial reduction & $1.5 \mathrm{~mm}$ & $1.0 \mathrm{~mm}-1.5 \mathrm{~mm}$ \\
\hline Finish Line & Circular shoulder $/$ chamfer $1.0 \mathrm{~mm}$ & Accentuated chamfer $1.0 \mathrm{~mm}$ \\
\hline
\end{tabular}

\subsection{Tooth Duplication, Mounting and Alignment}

Addition silicon impression material Dublisi ${ }^{\circledR}[15]$ was used to create duplication moulds as in Figures 1-3. Replicas of the prepared teeth were obtained using the polyurethane-based resin material, AlphaDie ${ }^{\circledR}$ MF (). AlphaDie ${ }^{\circledR}$ MF is used in many studies as dentine and supports bone substitute material despite the structural dissimilarity between the anisotropic tubular dentine and the isotropic polyurethane-based resin material. It aims to minimise the natural tooth's histological and anatomical variabilities [33-35]. All replicas were visually examined for defects using X3.5 magnification loupes. Samples were subsequently stored in a dry environment for at least $24 \mathrm{~h}$ and the following steps regarding the construction and fabrication of the replica were undertaken, as shown in Figures 4-9.

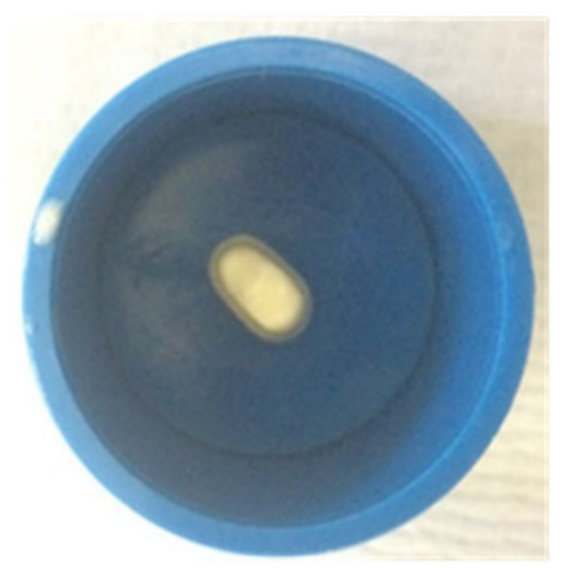

Figure 1. The tooth stacked in the centre of plastic cylindrical rings.

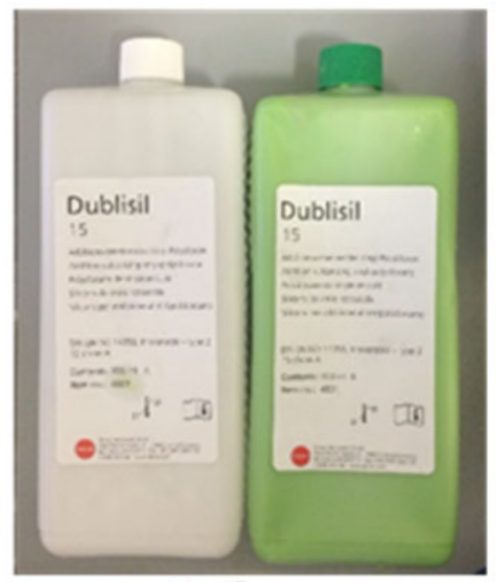

Figure 2. Dublisil ${ }^{\circledR} 15$. 


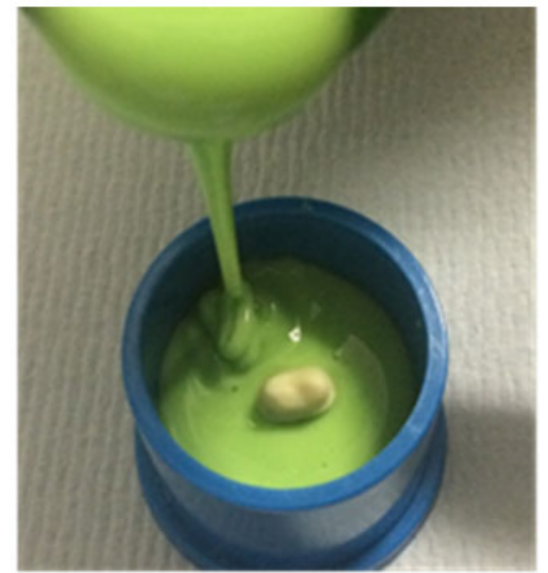

Figure 3. Gently pour the impression.

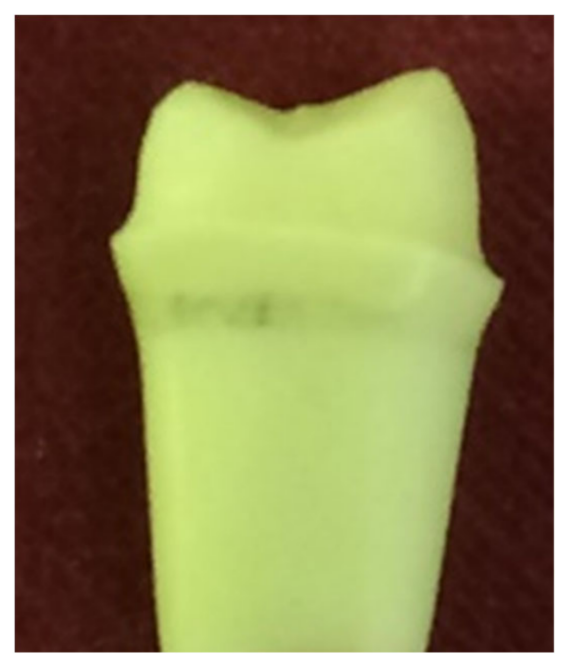

Figure 4. Original Frasaco prepared teeth of each group were marked $2 \mathrm{~mm}$ apical to the cementoenamel junction circumferentially.

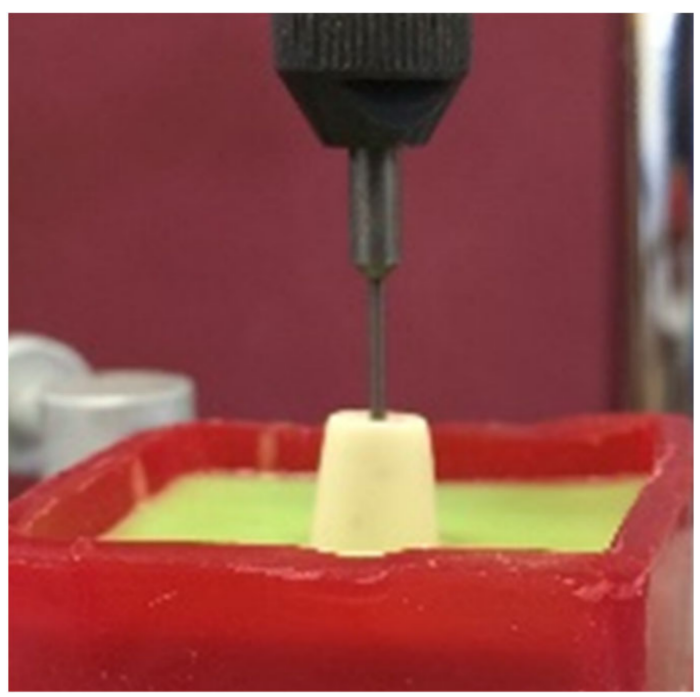

Figure 5. Teeth were then separately placed and stacked in an upside down vertical direction following their long axis with the help of a dental surveyor pin inserted in the typodont tooth screw slot. 


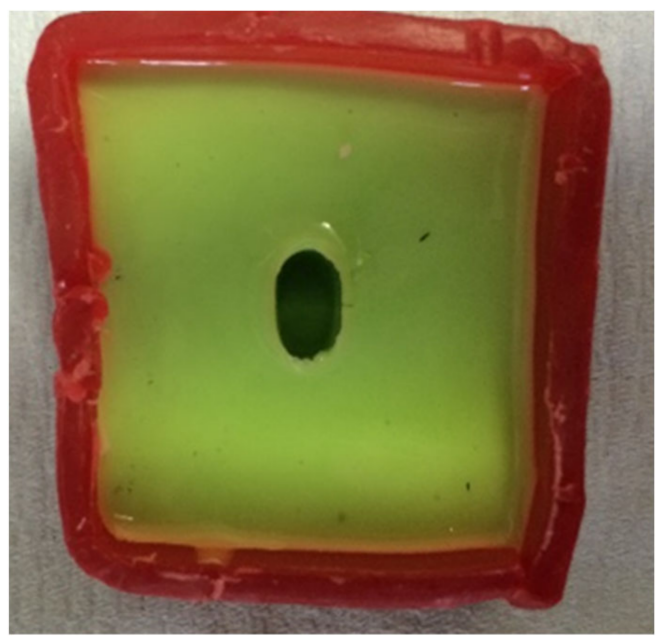

Figure 6. A wax boarded box container mounted on a $0^{\circ}$ degree tilted articulator table was filled with freshly mixed addition silicon impression material (Dublisil $\left.{ }^{\circledR} 15\right)$ to embed the prepared tooth until the marked line. This procedure was applied to both original prepared typodent teeth to fabricate 2 original moulds of the ideal teeth alignment of both groups which was used for the rest of the samples.

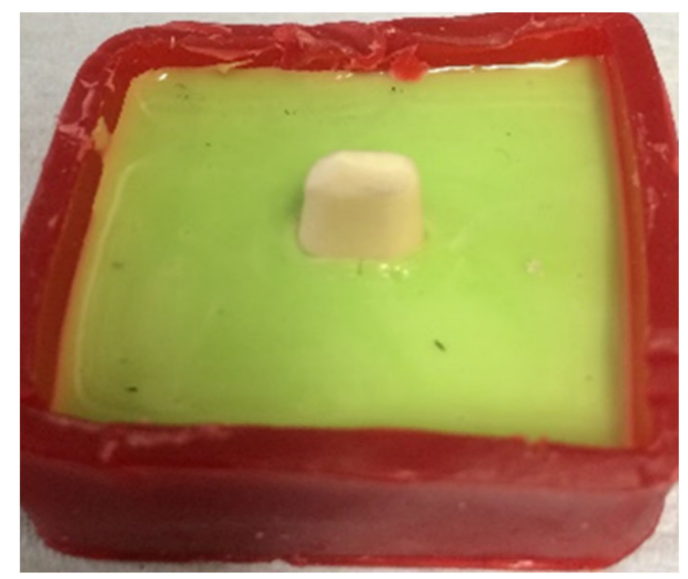

Figure 7. The duplicated samples then were separately painted with a thin layer of die separator spray and their coronal part was inserted in the alignment mould of their group.

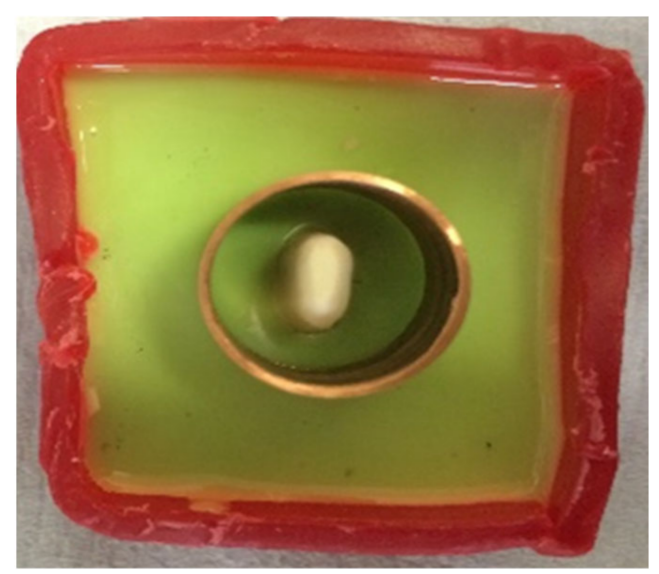

Figure 8. A copper ring was placed over the mould to evenly surround the sample root to ensure it was ready to fill with freshly mixed bone-like material AlphaDie ${ }^{\circledR}$ MF. 


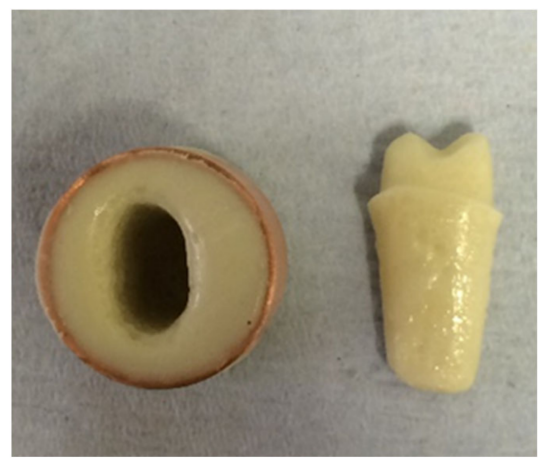

Figure 9. When it had initially set the sample was gently detached from the ring base leaving a space, this hollow simulates the alveolar bone socket which surrounds the natural teeth.

\subsection{Periodontal Ligament (PDL) Simulation}

Previous studies using static and dynamic fatigue testing have demonstrated the need to simulate the periodontal ligament [29,32]. This should resemble the natural physiological grade tooth mobility 0 and allow $50 \mu \mathrm{m}$ movement matching the natural PDL resilience $[20,21,29]$. To simulate the periodontal ligaments, a $200 \mu \mathrm{m}$ uniform thickness with the addition of light body silicon impression material (President Plus ${ }^{\circledR}$, Coltène, Altstätten, Switzerland) was injected around the root. It was injected slowly into the socket then the tooth was immediately reinserted in its position after the injection as depicted in Figure 10. The tooth was then confirmed to exhibit no physiologic tooth mobility (Grade 0) as per normal tooth mobility. Excess injection material was removed using size 15 and 11 surgical blades.

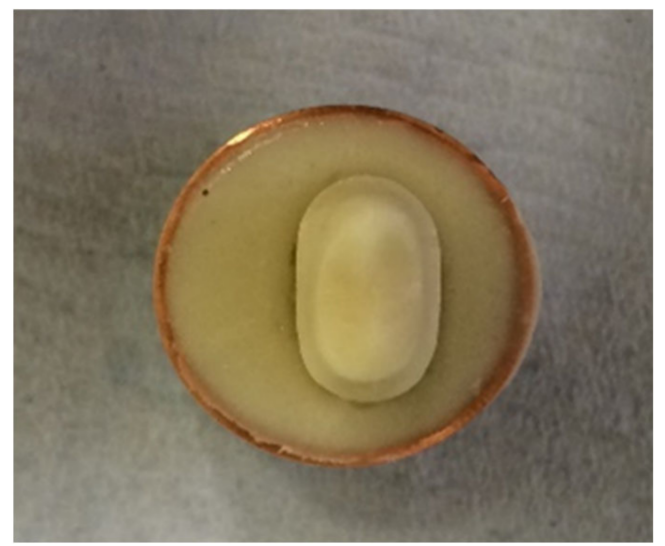

Figure 10. Addition light body silicon impression material (President Plus ${ }^{\circledR}$ ) injected and reinserted to simulate periodontal ligament.

\subsection{Crown Fabrication}

Crowns were fabricated on the master Frasaco tooth preparations. The InEos (inEos x5, Dentsply Sirona, Charlotte, NC, USA) system and CEREC inLab (Version 3.60) (VITA, Zahnfabric, Germany) were used for scanning and designing the crowns. Each milled crown was carefully examined using magnification (3.5×). Any defective crowns were discarded, and the remaining were tested. Satisfactory marginal and base adaptation and correct occlusal surface morphology were required before the crowns were deemed adequate for cementation.

\subsection{Crown Cementation}

The teeth were cleaned with a rubber cup and pumice using a low-speed handpiece. The crowns were cemented using material recommended by the manufacturer which was 
used in accordance with the prescribed instructions [31,32,36,37]. The cementation steps and agent used are highlighted below in Table 2.

Table 2. List of etchants, bonding agents and luting cement used in the study.

\begin{tabular}{ccccc}
\hline Material & Etching & Silanization & Bonding & Cementation \\
\hline $\begin{array}{c}\text { Monolithic Lithium } \\
\text { Disilicate IPS e.max CAD }\end{array}$ & $\begin{array}{c}\text { Hydroflouric Acid Gel } \\
5 \%(20 \mathrm{~s})\end{array}$ & Nil & $\begin{array}{c}\text { Scotchbond } \\
\text { Adhesive, 3M ESPE }\end{array}$ & $\begin{array}{c}\text { Rely X Unicem, 3M } \\
\text { ESPE }\end{array}$ \\
\hline PEEK by Juvora ${ }^{\mathrm{TM}}$ & Nil & Nil & $\begin{array}{c}\text { Scotchbond } \\
\text { Adhesive, 3M ESPE }\end{array}$ & $\begin{array}{c}\text { Rely X Unicem, 3M } \\
\text { ESPE }\end{array}$ \\
\hline
\end{tabular}

Standardised Cementation Techniques

A standardised cementation procedure was applied to ensure an adequate and consistent cementation force in order to achieve a uniform thickness of luting cement. A custom-made device attached to a tensometer (Lloyds Instrument Model LRX, Hampshire, UK) was used to deliver a constant force of $40 \mathrm{~N}$ over $3 \mathrm{~min}$ to simulate the finger pressure and equal distribution of force throughout the occlusal surface [32,35,38]. A tested and calibrated visible blue light (LED) light-curing unit was used to ensure complete polymerisation at the margins of the crown (Figure 11).

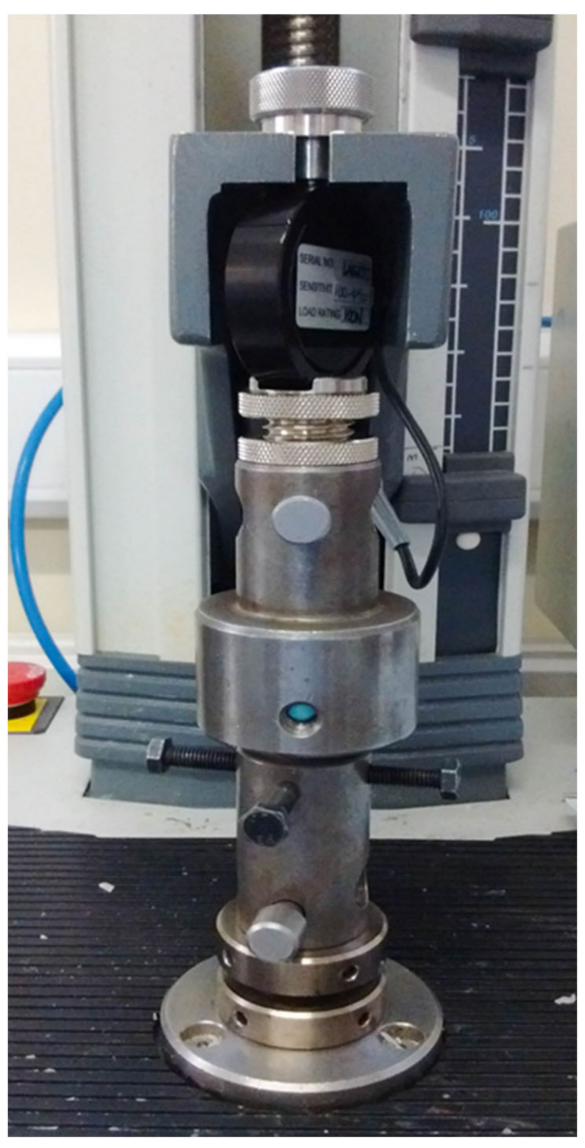

Figure 11. Final cementation settings by using the tensometer.

\subsection{Finishing and Polishing of the Samples}

Residual excess cement was removed with a plastic hand instrument. A standard procedure of cleaning and polishing the crowns and margins was used for all samples using the following sequence: brown and green silicone rubber points (Shofu Inc., Kyoto, Japan) and Sof-Lex ${ }^{\mathrm{TM}}$ finishing and polishing discs (3M ${ }^{\mathrm{TM}}$ ESPE, St Paul, MN, USA) in 
a low-speed handpiece. All the samples were left undisturbed for at least $1 \mathrm{~h}$ and kept immersed in a water solution at a constant of $37^{\circ} \mathrm{C}$ for at least $24 \mathrm{~h}$ before testing.

\subsection{Mechanical Testing}

\subsubsection{Static Testing}

A universal testing machine (Lloyds Instrument Model LRX) was used for this procedure. The teeth were mounted to the fixed base of the machine parallel to the crosshead. A crosshead with a speed of $1 \mathrm{~mm} / \mathrm{min}$ with a standard diameter ball head $(4.24 \mathrm{~mm})$ was used as a static compression axial load indenter [14,15] (Figure 12). A rubber dam $(2 \times 2 \mathrm{~cm})$ with a standard thickness of $1 \mathrm{~mm}$ was used as a stress breaker (Figure 13). The maximum compression force was recorded in Newton $(\mathrm{N})[32,38]$.

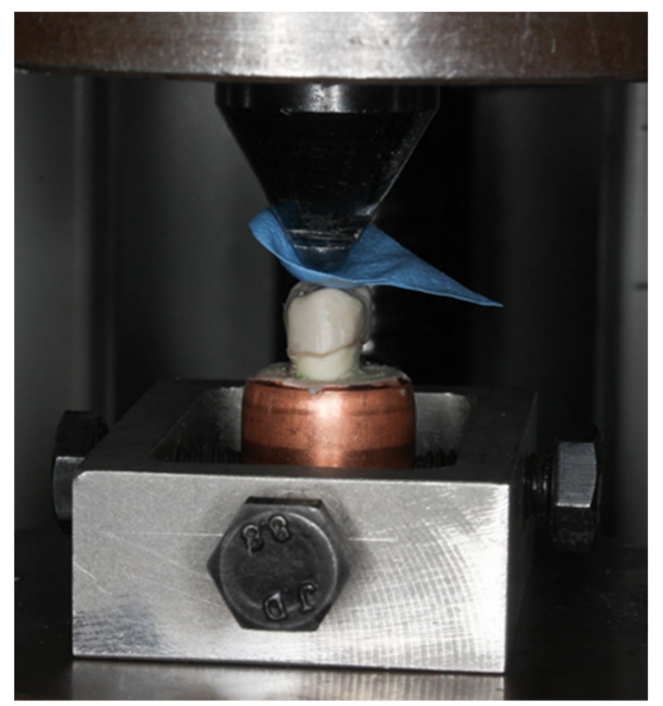

Figure 12. Marks were made initially on the inclination of both the buccal and palatal cusp.

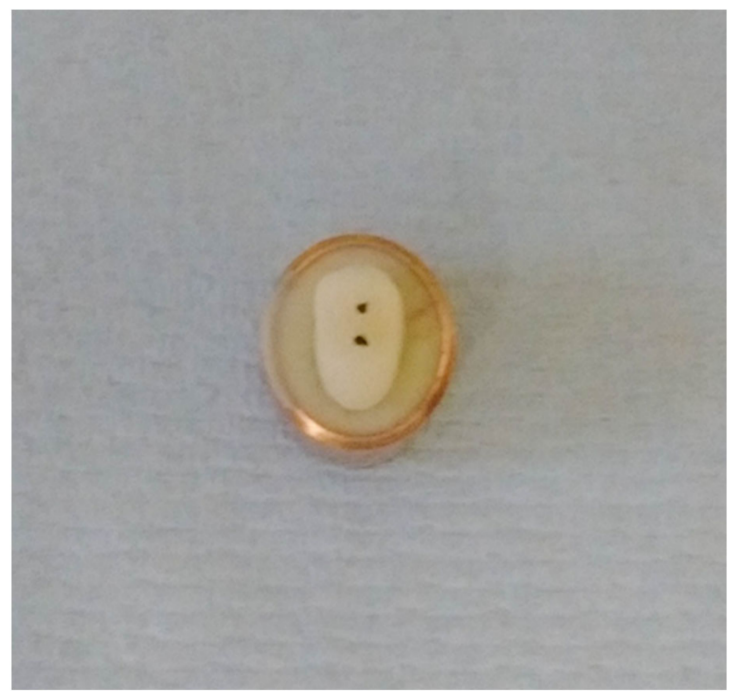

Figure 13. Sample set-up prior to testing.

\subsubsection{Dynamic Testing}

The specimens were mounted in the chewing simulator machine which has been designed and constructed by Professor Mair for a study assessing the fatigue limit and fatigue life in resin-bonded metal to enamel bonds [15,33] (Figure 14). It works by applying a repetitive axillary changeable load on the mounted specimens in a water bath with five fixed sample stations linked with a water temperature regulator made to simulate 
the intraoral environment. Variable movable metal discs were placed at the end of the five individual loading arms to generate and control the load magnification delivered on the samples at the other end by the indenters. In this test, we mounted the samples at $0^{\circ}$ degree in a $37^{\circ} \mathrm{C}$ water bath to be subjected to the adjustable spherical tip stainless-steel indenters (4.25 mm tip diameter with silicon cushion disc) attached to the other end of the arms. The uniaxial load direction arms holding indenters at their ends adjusted to occlude on two contact points on each crown, a lingual inclination of buccal cusp and buccal inclination of lingual cusp, these points were evaluated by a thin articulating paper [33]. Light body silicon cushions (President Plus ${ }^{\circledR}$ ) were placed between the loading arms and the indenters to act as the antagonist teeth PDL, reducing and absorbing the load effect. The load frequency was set at 1 Hertz, meaning one occluding cycle every second.

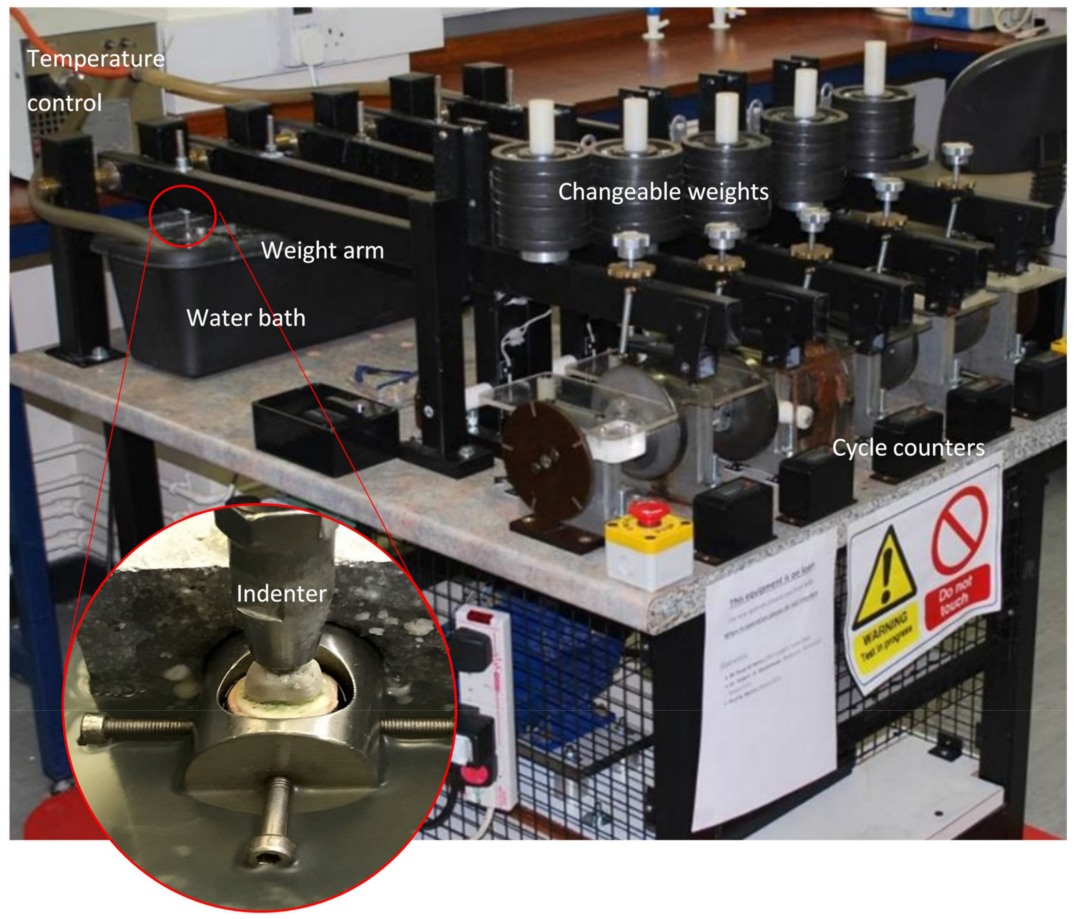

Figure 14. Chewing simulator machine.

\section{Fatigue Limit Experiments}

A staircase technique was chosen to determine the fatigue limits of the PEEK and IPS e.max ${ }^{\circledR}$ CAD crowns individually. This method started by loading the first fresh sample of each group with $453 \mathrm{~N}$ occlusal force $(4.0 \mathrm{Kg})$ for 5000 cycles at 1 Hertz cyclic frequency. When the 5000 cycles were completed or the crown fractured, the sample was removed and replaced with a new sample with a $0.5 \mathrm{~kg}$ increase of the loading disc (if it survived the 5000 cycles) or a decrease of the loading disc (if it failed prematurely). The fatigue limit was clearly identified when the samples survived three times under the same load after the 5000 cycles and sequentially fractured three times under the next higher load. Subsequently, the survival load (endurance load) was identified as the fatigue limit utilised to determine the fatigue life. The power calculation of previous studies showed that 10 to 20 samples were sufficient to identify the fatigue limit load for different dental materials. Thus, 20 samples for each group were allocated to be used for the fatigue limit test.

\section{Fatigue Life Experiments}

Accordingly, the fatigue limit load of each group was used to determine the fatigue life, which was identified as the number of cycles applied on the crowned teeth until they fractured under the assigned occlusal load. The number of samples used for each group depended on the power calculation assigned to identify if a significant difference was 
achieved between the control and test groups or not. In fatigue life test, more than one sample could be tested at the same time with different counters. The chewing simulator machine was set to run for 1,250,000 cycles at 1 Hertz cyclic frequency. However, automatic cut-off calculators, which calculate the number of applied cycles, will cut off the cyclic load and stop counting when the sample fractures.

\subsection{Mode of Fracture}

Burke's fracture mode analysis (Table 3) has been used extensively in assessing and describing the initial fracture pattern of extra-coronal prosthesis tested by in vitro study. It is due to its simplicity, reliability, and practicality for fracture observation and statistical analysis [32,38,39]. The fracture modes of each group and specimens were recorded.

Table 3. Description of different codes of fracture mode as per Burke's classification 1999.

\begin{tabular}{cc}
\hline Mode of Fracture & Description of Each Code \\
\hline Code 1 & Minimal fracture or crack in crown \\
\hline Code 2 & Less than half of crown lost \\
\hline Code 3 & Crown fracture through midline: half of crown displaced or lost \\
\hline Code 4 & More than half of crown lost \\
\hline Code 5 & Severe fracture of tooth and / or crown \\
\hline
\end{tabular}

\subsection{Fractographic Stereomicroscope Assessment}

Random samples from the PEEK group were selected for stereomicroscopic analysis. A total of three samples were selected initially and the best samples with the clearest view were chosen as depicted in Figures 19 and 20. The samples were cleaned thoroughly under running water to remove any debris or grease resulting from the testing. They were then sectioned parallel to the long axis of the teeth (Buehler IsoMet ${ }^{\circledR} 1000$ Precision Saw, Wooster, $\mathrm{OH}$, USA) (Figure 15). The samples were polished (Buehler METASERV ${ }^{\mathrm{TM}}$ ) to create a very fine surface utilising 1200 grit (P1200) finish.

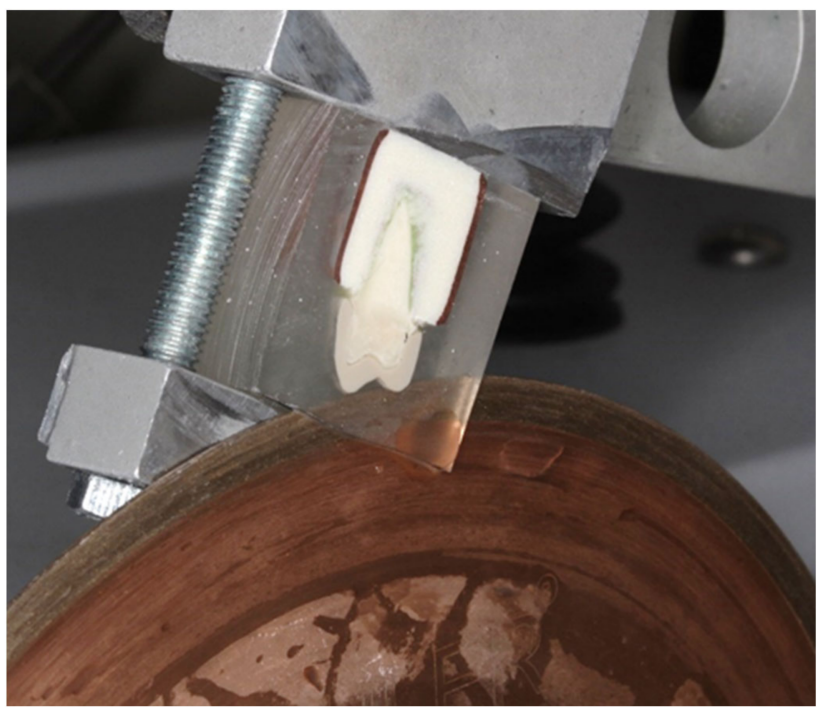

Figure 15. Cold cured acrylic blocks sectioned with diamond discs attached to a cutting machine.

The samples were examined under a stereomicroscope (ZEISS SteREO Discovery.V8, Medit, Seoul, Korea) under magnification of up to $8 \times$ zoom. The samples at the magnification were selected and processed using an imaging software package (AxioVision Rel. 4.8. ZEISS). 


\subsection{Digital Subtraction by 3-D Model Analysis}

A 3-dimensional (3D) model analysis was generated from 3 samples chosen randomly after each test and the samples with the best views were selected, as depicted in Figures 22 and 23. They were scanned before the tests and then cleaned thoroughly under running water to remove any debris or grease, followed by optical powder application for scanning CEREC powder VITA. Initially, the samples were then scanned using a 3D scanner (Identica Blue V 1.1.9.5, Medit, Seoul, Korea). A total of four constant points were selected to allow scanning thus enabling comparison from the sample. They were then processed by a finite element analysis (FEA) mesh software for 3D analysis and measurements (3-Matic ${ }^{\circledR}$ Research Version 10.0, Materialise 3-matic, Leuven, Belgium).

\section{Results}

\subsection{Fracture Strength}

The mean fracture strength for both groups was recorded in Newton (N) (Table 4). This was analysed using SPSS statistical package version 21.0. A $(p)$ level of 0.05 was used to detect any significant difference $(p=0.05)$. A normality test was done on the groups. Results with $p>0.05$ mean that the data from the mean fracture strength category are normally distributed. A one way Analysis of Variance (ANOVA) was performed to detect the level of significant difference between groups followed by post-hoc Tukey Pairwise comparisons to analyse which group was the one that demonstrated significant difference. The results show that there was a significant difference in fracture strength between the two groups (Table 4).

Table 4. Mean fracture strength, standard deviation, 95\% Confidence Interval (CI), and $p$ value for each group.

\begin{tabular}{ccc}
\hline Groups & $\begin{array}{c}\text { Monolithic Lithium } \\
\text { Disilicate IPS e.max CAD }\end{array}$ & PEEK by Juvora $^{\mathrm{TM}}$ \\
\hline Numbers & 10 & 10 \\
\hline Mean (Newton) & 703.4 & 2060.5 \\
\hline Standard Deviation & 47.2 & 250.9 \\
\hline $95 \%$ CI & $599.7 ; 807.1$ & $1956.8 ; 2164.2$ \\
\hline$p$ value & & \\
\hline
\end{tabular}

\subsection{Fatigue Limit}

IPS e.max ${ }^{\circledR}$ CAD crown-tooth samples failed consistently at a load lower than $2.0 \mathrm{~kg}$ $(=320 \mathrm{~N})$. Meanwhile, at a level of $1.5 \mathrm{~kg}(=284 \mathrm{~N})$ the samples survived the load for 5000 cycles (Figure 16). Thus, this study selected $1.5 \mathrm{~kg}(=284 \mathrm{~N})$ as the IPS e.max ${ }^{\circledR} \mathrm{CAD}$ crowns' fatigue limit load. PEEK crowns showed continued survival at higher loads. PEEK crown samples did not fracture but showed signs of deformation at higher survival loads of $11 \mathrm{~kg}(930 \mathrm{~N}$ ) and potentially more for 5000 cycles (Figure 17). Consequently, an occlusal load that is usually applied on the posterior teeth of $300 \mathrm{~N}$ to $500 \mathrm{~N}[14,28,34,40]$ was considered more appropriate at $5 \mathrm{~kg}(522 \mathrm{~N})$.

\subsection{Fatigue Life}

The highest limit of cycles was set to be $1,250,000$ representing $>5$ years of chewing. A total of six samples in each group were subjected to the fatigue life test under the selected fatigue limit (1.5 Kg for IPS e.max ${ }^{\circledR} \mathrm{CAD}$ crowns, $5.0 \mathrm{Kg}$ for PEEK crowns). The sample size power calculation was $100 \%$ for the mean readings of the 12 samples (Source-forge website). The $t$-test statistical analysis illustrates the highly significant difference between the mean values of the survived cycles between the two groups (Table 5). IPS e.max ${ }^{\circledR} \mathrm{CAD}$ crowns showed early failure after 96,315 to 157,591 cycles $($ mean $=133,470)$ (Table 6). However, PEEK crowns survived after 1,250,000 cycles but showed noticeable deformation in the form 
of dimpling and wear in the crown-indenter contact points which requires further analysis.

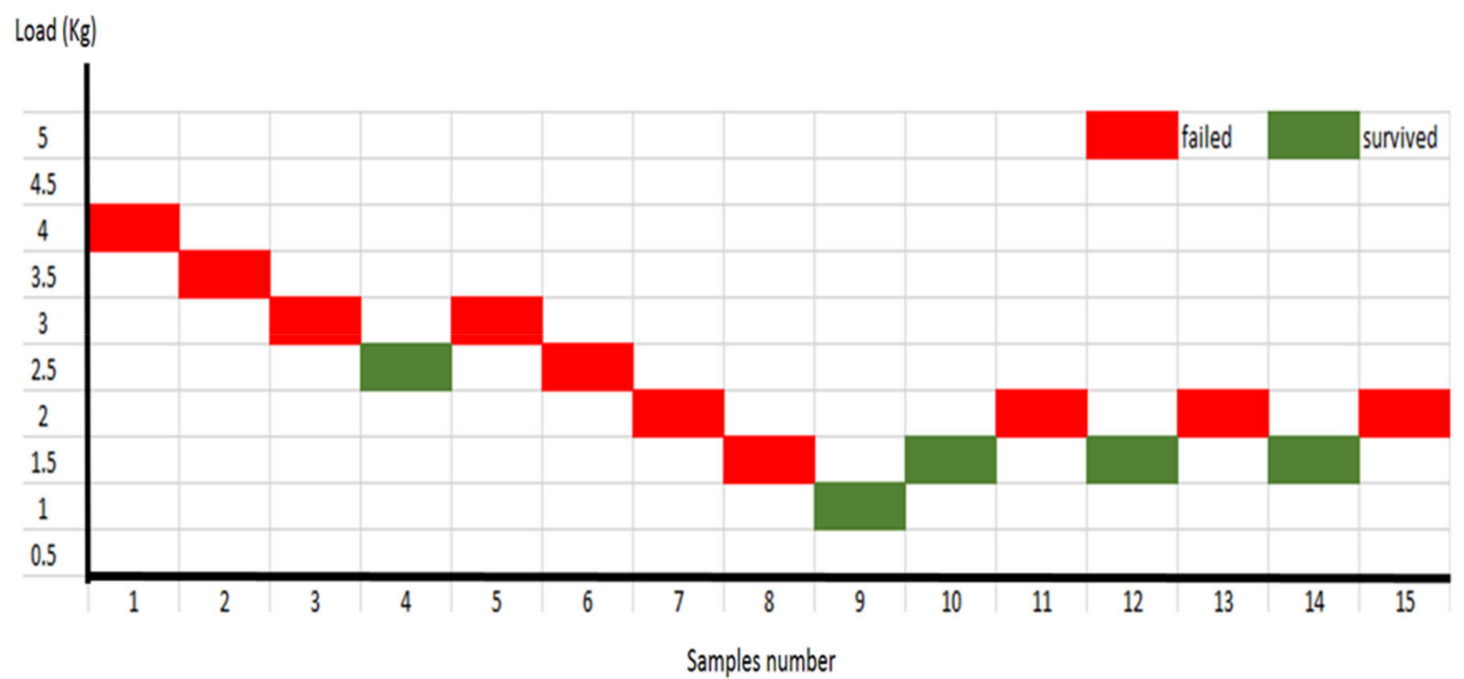

Figure 16. Fatigue limit staircase for IPS e.max ${ }^{\circledR} \mathrm{CAD}$ crowns.

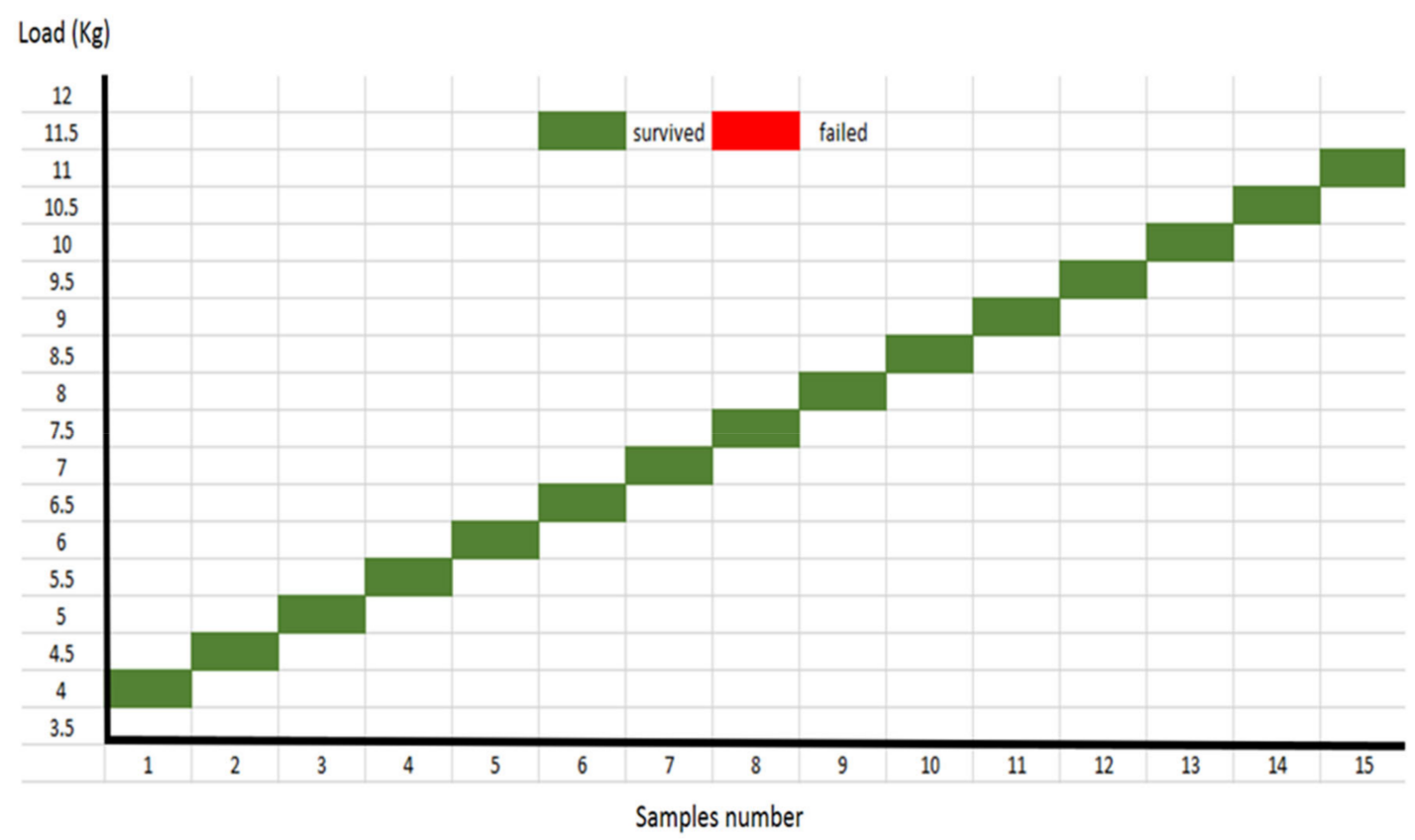

Figure 17. Fatigue limit staircase for PEEK crowns.

Table 5. $t$ test comparing the fatigue lives of each group, the mean number of survived cycles, number of samples, standard deviation (SD), T statistics, and $p$ value.

\begin{tabular}{ccc}
\hline Groups & PEEK by Juvora $^{\text {TM }}$ & $\begin{array}{c}\text { Monolithic Lithium Disilicate IPS e.max } \\
\text { CAD }\end{array}$ \\
\hline Mean & $>1,250,000$ & 133,470 \\
\hline Variance & 0 & $4.68 \times 10^{8}$ \\
\hline Number of Samples & 6 & 6 \\
\hline SD & 0 & $21,631.95$ \\
\hline T Statistics & & \\
\hline$p$-value & \multicolumn{2}{|}{} \\
\hline
\end{tabular}


Table 6. IPS e.max CAD fatigue life test.

\begin{tabular}{cc}
\hline Sample No & Number of Cycles to Fracture \\
\hline 1 & 147,645 \\
\hline 2 & 96,315 \\
\hline 3 & 157,591 \\
\hline 4 & 140,711 \\
\hline 5 & 122,612 \\
\hline 6 & 135,946 \\
\hline Mean & 133,470 \\
\hline
\end{tabular}

\subsection{Failure Mode Analysis}

After a failure in any test, the fracture mode of IPS e.max ${ }^{\circledR} \mathrm{CAD}$ crowns was assessed according to Burke's classification, whereas, Kruskal-Wallis analysis was used to classify the fracture mode after the compressive strength static test. It exhibited a significant difference $(p=0.000)$ between the groups (Tables 7 and 8$)$. In the fatigue testing, the noticeable failure was demonstrated only by the IPS e.max group. The majority of the fracture modes were between code three and five, meaning that half of the crown or more was displaced or lost in code three and four or severe fracture for the crown and tooth in code five (Table 8).

Table 7. Mode of fracture for each sample within each group after the static compressive testing using Burke's classification 1999.

\begin{tabular}{cccccc}
\hline Groups & Code 1 & Code 2 & Code 3 & Code 4 & Code 5 \\
\hline $\begin{array}{c}\text { Monolithic Lithium Disilicate IPS e.max } \\
\text { CAD }\end{array}$ & 0 & 0 & 4 & 6 & 0 \\
\hline PEEK by Juvora $^{\text {TM }}$ & 0 & 0 & 0 & 0 & 10 \\
\hline
\end{tabular}

Table 8. Mode of fracture in IPS e.max CAD after fatigue tests using Burke's classification 1999.

\begin{tabular}{cccccc}
\hline Test (No of Fractured Samples) & Code $\mathbf{1}$ & Code $\mathbf{2}$ & Code $\mathbf{3}$ & Code $\mathbf{4}$ & Code 5 \\
\hline Fatigue limit test (10) & 0 & 0 & 2 & 4 & 4 \\
\hline Fatigue life test (6) & 0 & 0 & 0 & 2 & 4 \\
\hline
\end{tabular}

\subsection{Fractographic Stereomicroscope Analysis}

A cross-section of a cemented non-tested PEEK crown showed a 180-200 $\mu \mathrm{m}$ uniform thickness of simulated PDL, an intact PEEK crown, cement interface within the optimal thickness $10-30 \mu \mathrm{m}$ and intact underlying polymer AlphaDie ${ }^{\circledR} \mathrm{MF}$ tooth (Figure 18). The cross-section of the specimen under a stereomicroscope with a magnification of $100 \mu \mathrm{m}$ is shown in Figure 19. Figure 20 shows the PEEK crown after the compressive test. After the dynamic tests, the PEEK crowns looked physically intact but with compressive plastic destruction of the crown, cement interface and supporting dentine polymer replica (Figure 21). 


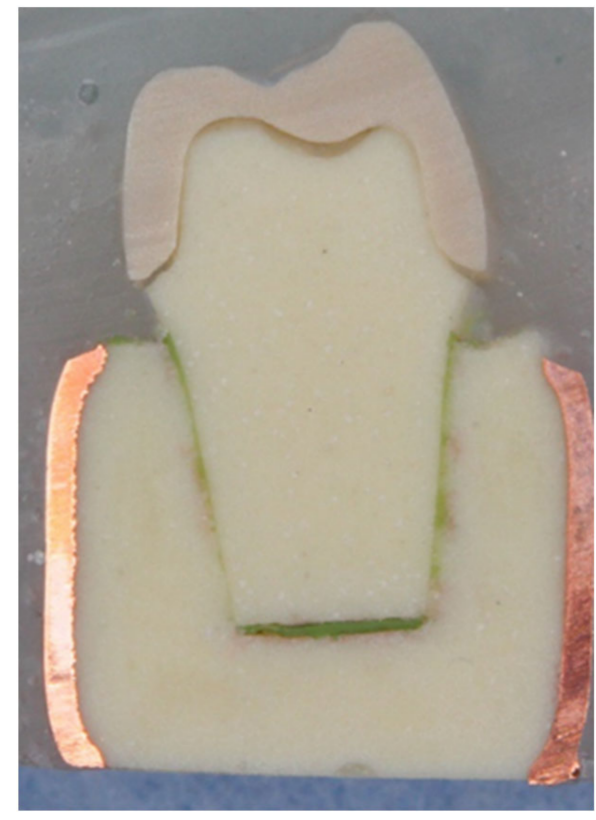

Figure 18. The PDL substitute is the green interface between the tooth structure and surrounding bone replica.

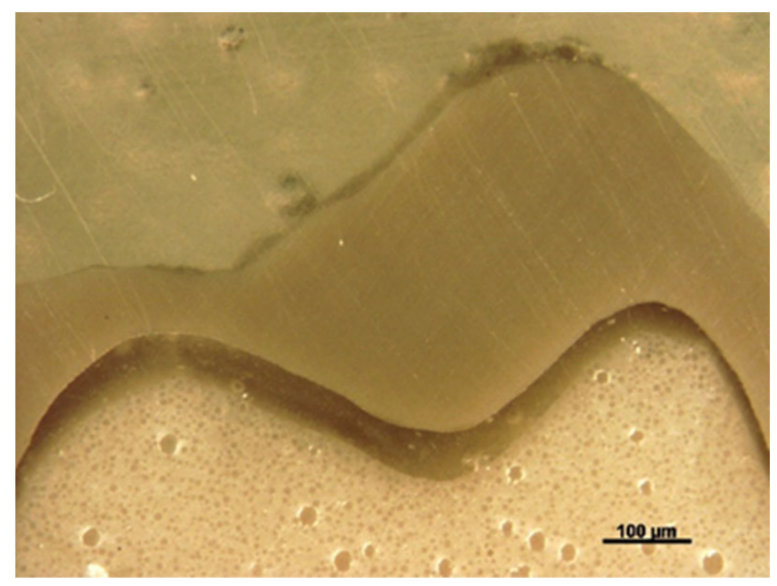

Figure 19. The sectioned photograph of microscopically analysed PEEK crowns before load initiation at $100 \mu \mathrm{m}$.

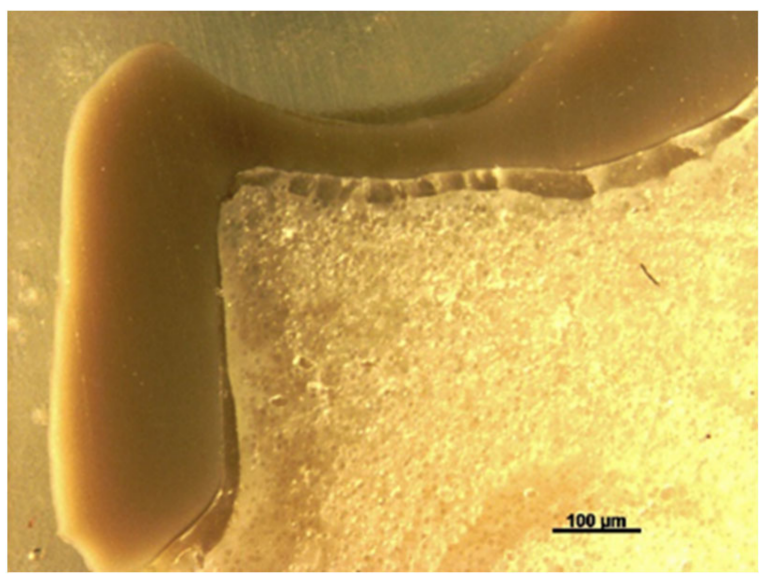

Figure 20. The sectioned photograph of microscopically analysed PEEK crowns after load initiation at $100 \mu \mathrm{m}$. 


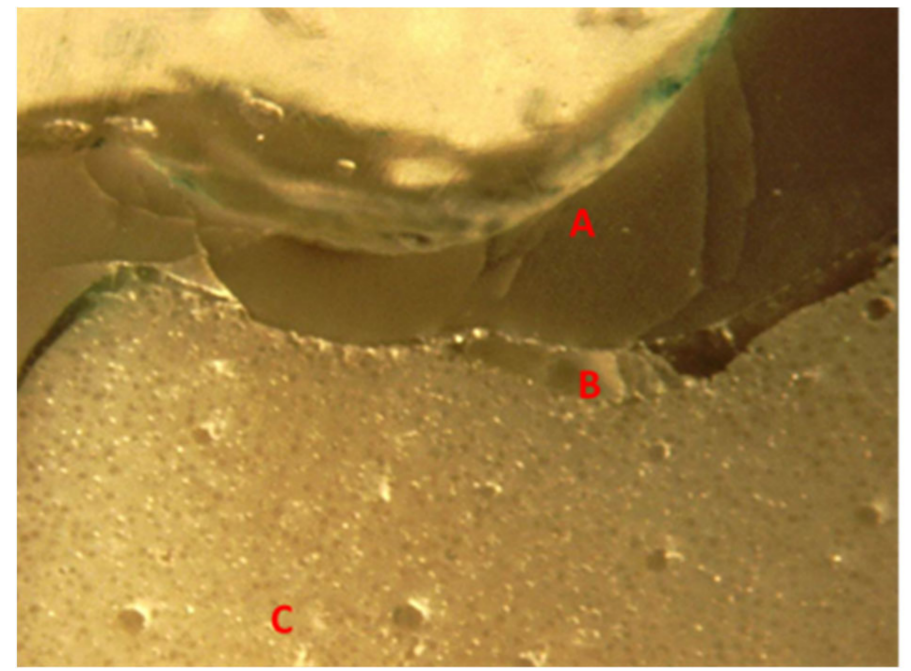

Figure 21. Stereomicroscope image of 1,250,000 cycles fatigue tested (A) damaged PEEK crown (B) crunched and cracked RelyXTM TM Unicem cement interface (C) deformed AlphaDie ${ }^{\circledR M F}$ Polymer tooth.

\subsection{D Digital Subtraction Analysis}

A 3D model after each test was generated for a non-failed PEEK sample and analysed. The compressive static test result is illustrated in Figures 22 and 23. It shows the PEEK crown sample after undergoing static load compression and dynamic testing, respectively. In dynamic testing, samples were scanned before being subjected to their fatigue limit loads for 5000 cycles and the fatigue life for 1,250,000 cycles. IPS e.max ${ }^{\circledR}$ CAD survived crowns did not show any noticeable changes, distortion, or wear. However, PEEK crowns showed some slight noticeable deformation at many walls as depicted in Figure 23.
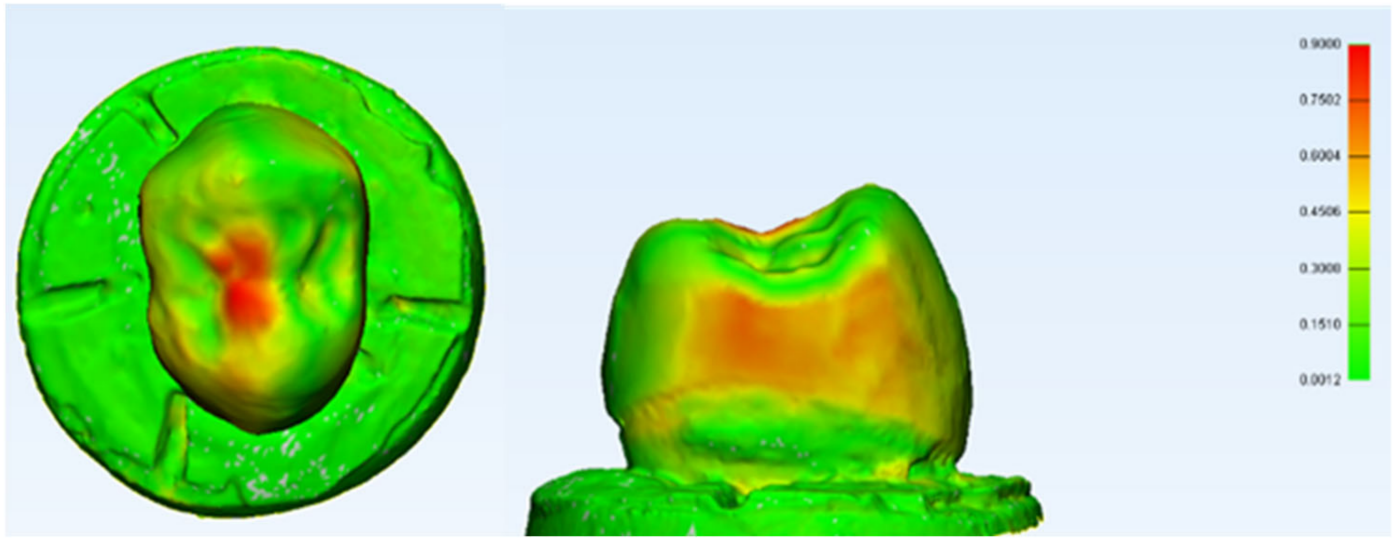

Figure 22. 3D submerged pre-and post-test scanning for a PEEK crown after the static compressive test. The technique was colour map-based, as depicted in the above figure. The red represented the most deformed area, the yellow was the lesser deformed area while the green was the area that remained physically unchanged compared to the shape prior to the loading. From the histogram data, the area of deformation happened in the range of $0.0012 \mathrm{~mm}$ to $0.90 \mathrm{~mm}$ with a mean of $0.1559 \mathrm{~mm}$ and a standard deviation (SD) of 0.1586 . 


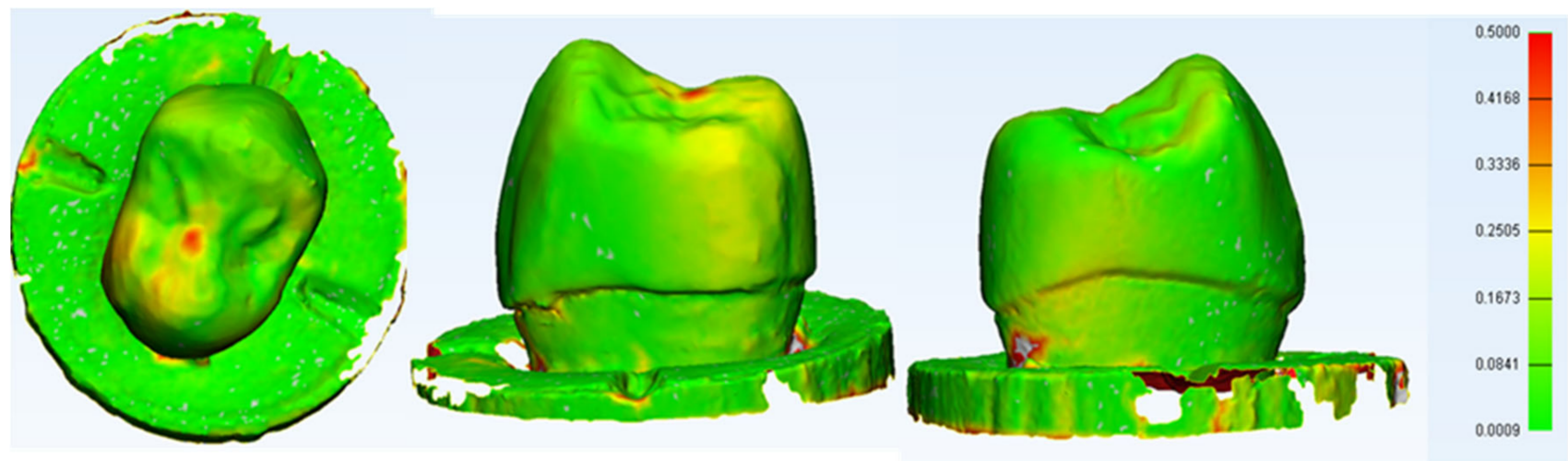

Figure 23. The most visible change was at the contact point between the crown and the indenter which deformed apically by an average of $0.7 \mathrm{~mm}$ which represents the overall maximum deformation point. The deformation in the axial walls were generally outward by less than $0.2 \mathrm{~mm}$. The mean of distortion is $0.0913 \mathrm{~mm}(\mathrm{SD}=0.092)$.

\section{Discussion}

Multiple techniques have been utilised in this in vitro study to mimic the situation close to real clinical application. AlphaDie ${ }^{\circledR} \mathrm{MF}$ was used in this study as it is closely matches the dentin elastic modules (14,800 MPa). This technique can bond to composite luting cement and it can be identically duplicated after the preparation of the intended sample number, which also significantly minimises the natural teeth variables and the variety in the tooth preparations [30,31]. In addition, $200 \mu \mathrm{m}$ uniform thickness of President Plus ${ }^{\circledR}$ will resemble the natural physiological grade zero tooth mobility and allow $50 \mu \mathrm{m}$ movement to simulate the clinical presence of periodontal ligament, which has been illustrated in Figure 10 [20]. Resin cement (Rely X Unicem, 3M ${ }^{\mathrm{TM}}$ ESPE, St. Paul, MN, USA) is a self-adhesive resin cement with a modulus of elasticity of $8 \mathrm{GPa}$ with the aim of achieving micromechanical and/or chemical bond to the tooth structure. It was used in this study due to its clinical handling simplicity, less technique sensitivity, and is suitable for both types of ceramic and polymer-based crowns $[31,36]$. Furthermore, the selection of premolar tooth in this study is due to the easiness to detect the contact point during testing and it is the conventionally used tooth selected for in vitro study [41,42]. Milled CAD/CAM PEEK crowns were selected as the test group due to their higher physical and mechanical properties of CAD/CAM PEEK crowns and bridge compared to pressed granular or pellets PEEK $[38,43]$. Machined lithium disilicate was chosen as a tested group due to similarity in its fabrication and manufacturing methodologies [6]. It also has comparable preparation requirements in both manufacturers' guidelines. Due to the novelty of PEEK material as a crown, the manufacturers' guidelines for crown preparation were lacking. Thus, to control the variation, detailed preparation guidelines for e.max crowns were applied to both crowns except the design of the finish line.

The null hypothesis for this study was rejected as the PEEK crown showed a statistically significant difference in the mean fracture strength compared to the control group. The results of this study suggest that the novel PEEK crowns had higher fracture load by using a static test in vitro compared to the monolithic e.max CAD. This was mostly due to the material nature in which it consisted of a thermoplastic polymer chain which allowed plastic deformation to occur under mechanical loading. The maximum fracture load by the PEEK crown was significantly higher than normal mastication with a mean load of 2060.5 Newton ( \pm SD $250.9 \mathrm{~N}$ ) compared to normal masticatory forces on posterior premolar teeth which can be up to $300 \mathrm{~N}$ [44]. These positive findings greatly exceed the normal mastication force on posterior teeth which amounts to around 300-500 N. Nonetheless, the influence of other aspects such as variable preparation design and the effect of the thickness and type of luting cement used were not assessed in this study and it is important to assess the influence of these parameters in a future study. 
Dynamic cyclic testing was intended to evaluate a material under interchangeable conditions. For dental material, the dynamic fatigue test is expected to simulate the oral clinical conditions and to preliminarily test the dental material's clinical performance utilising an in vitro modelling laboratory study. The accumulative fatigue stress had shown to be the most common reason for dental prosthesis failure [24,25]. Thus, it seems logical to investigate the probability of the crown failure from that aspect. In this study PEEK crowns, have been evaluated under fatigue testing, which is designed to simulate to some extent the actual chewing mechanism, which will obtain higher reliability of predicting the long-term survival of the dental crown [35,44-47]. The nature of PEEK material as a polymer-based material with higher elasticity with a modulus of elasticity of 3.6 Gpa is the reason PEEK crowns can absorb a very high occlusal load shock and survive significantly longer than lithium disilicate ceramic crowns (Modulus of elasticity $95 \pm 5 \mathrm{GPa}$ ).

Furthermore, the digital subtraction analysis showed that the PEEK crowns deformed in different directions and may be worn in the contact point to compensate for the load applied. In the meantime, the survived ceramic lithium disilicate crowns did not show any deformation before fracture due to their brittleness and disability to deform without fracturing. In fatigue life testing, the data were not consistent within the lithium disilicate group (intra-group variation). Still, the difference between groups (inter-group variation) is significant and this outweighed the large intra-group variation mentioned above. Hence, given the substantial intra-group variation, it is reasonable to accept the data from this investigation based on six samples for each group.

Fractographic analysis provides a further structural analysis of fractography in prosthetic dentistry under the stereomicroscope and scanning electron microscope. Detailed characteristics and effects of different materials within the crown-tooth complex under simulated loading can be assessed. The fracture mode analysis shows that PEEK crowns exhibited significantly higher fracture resistance compared to the lithium disilicate. All specimens of PEEK crowns had shown the capability to withstand higher simulated loading without introducing cracks and fractures on the occlusal surfaces. Conventional ceramics in dentistry generally have low flexure strength; the critical strain of dental ceramics is very low. The material can withstand deformation of approximately $0.1 \%$ before fracturing $[1,2,48]$. Constant repetitive loading and fluctuating stresses and strain may contribute to dental ceramic failure [2]. Furthermore, the presence of crazing and invisible microcracks initiated in the surface layer during the crown preparation by the milling machine may quickly be propagated when the load is applied [49]. Although, there is no study, to the author's knowledge, comparing pressed and milled full-coverage ceramic crowns, Yildiz et al., (2013) have reported that the ceramic onlays fabricated by the pressed technique show higher fracture resistance than ceramic onlays fabricated by CAD CAM technology [35]. Unlike the polymer derived material, the presence of water together with the constant cyclic stress in this test could act as a hydraulic piston which led to an increase in the stress at the crack end of ceramics. It has been found that this combination could result in fatigue failure of the ceramic restoration by up to $50 \%[15,50]$.

Fundamentally, the complexity of the tooth crown in this study such as the internal microstructure, composition, and configuration are best analysed under a specific magnification, for example, utilising a stereomicroscope [43]. A sample of a crown tooth complex from a PEEK crown was sectioned, polished adequately and evaluated at the structure level of approximately $100 \mu \mathrm{m}$. Prior to the testing, there was a continuous homogeneity on the lower border of the crown, resin cement interface, and underlying tooth structure within the tooth crown complex of the PEEK crown under $100 \mu \mathrm{m}$, as depicted in Figure 19. Essentially, a PEEK crown undergoes plastic deformation once it has exceeded its fracture resistant and scores code five on Burke's fracture mode analysis, which highlights the catastrophic deformation and failure due to this complex tooth-cement-restoration. There was continuous deformation on the margin of the tooth structure, microcracks on the tooth margin and highly compromised structure of the underlying luting cement representing a catastrophic failure of the structural integrity of the samples as depicted in Figures 20 and 21. 
A digital subtraction using 3D analysis was made in this study for a random sample of specimens from the PEEK crown group. It showed that a PEEK crown in the sample had coronal and lateral deformation up to $0.9 \mathrm{~mm}( \pm \mathrm{SD} 0.1586)$ on the stressed area highlighted by red zonal distribution. The highlighted deformations are also only concentrated on the occlusal and mesial/distal aspects of the crown, highlighting the unpredictable nature of the physical and mechanical properties of the crown under a constant simulated static loading. This was an initial finding; however, it allowed a preliminary estimation of the area that deformed the most and a rough calculation of the deformation area. Nonetheless, further studies are necessary which utilise findings that are better elaborated by using the Finite Element Analysis (FEA) technique, which can accurately measure the stress distribution of the area of interest [51-54].

This study aimed to mimic, as much as possible, the clinical condition in a simulated oral environment. Nonetheless, there were a few limitations, such as the study only using replica teeth to ensure homogeneity of the samples and one static point selected from the sample as compared to various morphological anatomies of the tooth structures. In future, various testing principles and methodologies such as finite element analysis and clinical trials are very much desirable. The findings of this study showed a potential exciting and additional benefit of using PEEK in terms of mechanical structural integrity strength and durability. These findings further consolidated the usage of PEEK in dentistry $[55,56]$. In future works, comparison with other available polymers commonly used in dentistry, particularly polymethylmethacrylate (PMMA), is desirable. It might also act as a platform for further investigations on newer high-performance polymers such as PEKK [57-59].

\section{Conclusions}

This laboratory-based fatigue testing study can conclude that PEEK is a very promising dental material with desirable mechanical behaviour. It showed greater fracture resistance and in the fatigue limit test, and showed a significantly higher ability to withstand occlusal loads without signs of failure in comparison to lithium disilicate crowns by more than eight times. Monolithic PEEK crowns showed a significantly higher survival rate and significantly less catastrophic failure mode under higher fatigue load tests than clinically successful lithium disilicate crowns in the fatigue life test. In the findings, PEEK crowns seemed to survive in both techniques, the fatigue limit and the life test. However, at a microscopic level, PEEK crowns failed at one point within the 1,250,000 occluding load cycles, and thus need further investigation. Further clinical and laboratory studies are needed to investigate PEEK's success as a crown material and improve its marginal adaptation and aesthetic properties for PEEK crowns.

Author Contributions: Conceptualization, N.M., M.S.A., S.A.; Methodology, N.M.; Software, N.M., M.S.A., S.A.; Validation, N.M., M.S.A., S.A.; Formal Analysis, N.M., M.S.A., S.A.; Investigation, N.M., M.S.A., S.A.; Writing-Original Draft Preparation, N.M., M.S.A., S.A.; Writing-Review and Editing, N.M., M.S.A., S.A.; Supervision, N.M.; Funding Acquisition, N.M. All authors have read and agreed to the published version of the manuscript.

Funding: This research received no external funding.

Institutional Review Board Statement: Not applicable.

Informed Consent Statement: Not applicable.

Data Availability Statement: Not applicable.

Acknowledgments: The author would like to thank the deanship of scientific research at Majmaah University for the project (no. R-2022-40).

Conflicts of Interest: The authors declare no conflict of interest. 


\section{References}

1. Van Noort, R.; Barbour, M.E. Introduction to Dental Materials, 4th ed.; Elsevier: Amsterdam, The Netherlands, 2013.

2. Anusavice, K.J.; Shen, C.; Rawls, H.R. Phillips' Science of Dental Materials; Elsevier: Amsterdam, The Netherlands, 2013.

3. Anusavice, K.; Zhang, N.-Z. Chemical Durability of Dicor and Fluorocanasite-based Glass-ceramics. J. Dent. Res. 1998, 77, 1553-1559. [CrossRef] [PubMed]

4. Denry, I.L.; Holloway, J.A.; Rosenstiel, S.F. Effect of ion exchange on the microstructure, strength, and thermal expansion behavior of a leucite-reinforced porcelain. J. Dent. Res. 1998, 77, 583-588. [CrossRef] [PubMed]

5. Alauddin, M.S. A Review of Polymer Crown Materials: Biomechanical and Material Science. J. Clin. Diagn. Res. 2019. [CrossRef]

6. Sailer, I.; Makarov, N.A.; Thoma, D.S.; Zwahlen, M.; Pjetursson, B.E. All-ceramic or metal-ceramic tooth-supported fixed dental prostheses (FDPs)? A systematic review of the survival and complication rates. Part I: Single crowns (SCs). Dent. Mater. 2015, 31, 603-623. [CrossRef]

7. Denry, I.; Holloway, J.A. Ceramics for Dental Applications: A Review. Materials 2010, 3, 351-368. [CrossRef]

8. Kurtz, S.M. PEEK Biomaterials Handbook; William Andrew: Norwich, NY, USA, 2011; pp. 1-117.

9. Brown, S.A.; Hastings, R.S.; Mason, J.J.; Moet, A. Characterization of short-fibre reinforced thermoplastics for fracture fixation devices. Biomaterials 1990, 11, 541-547. [CrossRef]

10. Green, S.; Schlegel, J. A Polyaryletherketone Biomaterial for Use in Medical Implant Applications; Rapra Technology Limited: Shawbury, UK, 2001.

11. Toth, J.M.; Wang, M.; Estes, B.; Scifert, J.L.; Seim, H.B.; Turner, A.S. Polyetheretherketone as a biomaterial for spinal applications. Biomaterials 2006, 27, 324-334. [CrossRef]

12. Elmougy, A.; Schiemann, A.M.; Wood, D.; Pollington, S.; Martin, N. Characterisation of machinable structural polymers in restorative dentistry. Dent. Mater. 2018, 34, 1509-1517. [CrossRef]

13. Morena, R.; Beaudreau, G.M.; Lockwood, P.E.; Evans, A.L.; Fairhurst, C.W. Fatigue of Dental Ceramics in a Simulated Oral Environment. J. Dent. Res. 1986, 65, 993-997. [CrossRef]

14. Fadeeva, I.V.; Trofimchuk, E.S.; Forysenkova, A.A.; Ahmed, A.I.; Gnezdilov, O.I.; Davydova, G.A.; Kozlova, S.G.; Antoniac, A.; Rau, J.V. Composite Polyvinylpyrrolidone-Sodium Alginate-Hydroxyapatite Hydrogel Films for Bone Repair and Wound Dressings Applications. Polymers 2021, 13, 3989. [CrossRef]

15. Padipatvuthikul, P.; Mair, L.H. Comparison of Shear Bond Strength, Fatigue Limit and Fatigue Life in resin-bonded metal to enamel bonds. Dent. Mater. 2008, 24, 674-680. [CrossRef] [PubMed]

16. Mair, L.; Langfield, A.; Walton, R.; Mansour, Y. Correlation of shear strength, fatigue limit and fatigue life of six high impact denture resins. Dent. Mater. 2011, 27, e64-e65. [CrossRef]

17. Drummond, J.L.; Bapna, M.S. Static and cyclic loading of fiber-reinforced dental resin. Dent. Mater. 2002, 19, 226-231. [CrossRef]

18. Hayashi, M.; Sugeta, A.; Takahashi, Y.; Imazato, S.; Ebisu, S. Static and fatigue fracture resistances of pulpless teeth restored with post-cores. Dent. Mater. 2008, 24, 1178-1186. [CrossRef]

19. Sakaguchi, R.L.; Douglas, W.H.; DeLong, R.; Pintado, M.R. The wear of a posterior composite in an artificial mouth: A clinical cor-relation. Dent. Mater. 1986, 2, 235-240. [CrossRef]

20. Wolfart, S.; Ludwig, K.; Uphaus, A.; Kern, M. Fracture strength of all-ceramic posterior inlay-retained fixed partial dentures. Dent. Mater. 2007, 23, 1513-1520. [CrossRef]

21. McCabe, J.F.; Carrick, T.E.; Chadwick, R.G.; Walls, A.W.G. Alternative approaches to evaluating the fatigue characteristics of materials. Dent. Mater. 1990, 6, 24-28. [CrossRef]

22. Stock, V.; Schmidlin, P.R.; Merk, S.; Wagner, C.; Roos, M.; Eichberger, M.; Stawarczyk, B. PEEK Primary Crowns with Co-baltChromium, Zirconia and Galvanic Secondary Crowns with Different Tapers-A Comparison of Retention Forces. Materials 2016, 9, 187. [CrossRef]

23. Wagner, C.; Stock, V.; Merk, S.; Schmidlin, P.R.; Roos, M.; Eichberger, M.; Stawarczyk, B. Retention Load of Telescopic Crowns with Different Taper Angles between Cobalt-Chromium and Polyetheretherketone Made with Three Different Manufacturing Processes Examined by Pull-Off Test. J. Prosthodont. 2016, 27, 162-168. [CrossRef]

24. Wiskott, H.W.; Nicholls, J.I.; Belser, U.C. Stress fatigue: Basic principles and prosthodontic implications. Int. J. Prosthodont. 1995, 8, 105-116.

25. Zhang, Y.; Sailer, I.; Lawn, B.R. Fatigue of dental ceramics. J. Dent. 2013, 41, 1135-11347. [CrossRef] [PubMed]

26. Lohbauer, U.; von der Horst, T.; Frankenberger, R.; Krämer, N.; Petschelt, A. Flexural fatigue behavior of resin composite dental restoratives. Dent. Mater. 2003, 19, 435-440. [CrossRef]

27. Tannous, F.; Steiner, M.; Shahin, R.; Kern, M. Retentive forces and fatigue resistance of thermoplastic resin clasps. Dent. Mater. 2012, 28, 273-278. [CrossRef] [PubMed]

28. Kassem, A.S.; Atta, O.; El-Mowafy, O. Fatigue Resistance and Microleakage of CAD/CAM Ceramic and Composite Molar Crowns. J. Prosthodont. 2011, 21, 28-32. [CrossRef] [PubMed]

29. Almarza, R.; Ghassemieh, E.; Shahrbaf, S.; Martin, N. The effect of crown fabrication process on the fatigue life of the tooth-crown structure. Mater. Sci. Eng. C 2019, 109, 110272. [CrossRef] [PubMed]

30. Kohorst, P.; Herzog, T.J.; Borchers, L.; Stiesch-Scholz, M. Load-bearing capacity of all-ceramic posterior four-unit fixed partial dentures with different zirconia frameworks. Eur. J. Oral Sci. 2007, 115, 161-166. [CrossRef] 
31. Sarafidou, K.; Stiesch, M.; Dittmer, M.P.; Jörn, D.; Borchers, L.; Kohorst, P. Load-bearing capacity of artificially aged zirconia fixed dental prostheses with heterogeneous abutment supports. Clin. Oral Investig. 2011, 16, 961-968. [CrossRef]

32. Shahrbaf, S.; van Noort, R.; Mirzakouchaki, B.; Ghassemieh, E.; Martin, N. Fracture strength of machined ceramic crowns as a function of tooth preparation design and the elastic modulus of the cement. Dent. Mater. 2014, 30, 234-241. [CrossRef]

33. Tsitrou, E.A.; Helvatjoglu-Antoniades, M.; van Noort, R. A preliminary evaluation of the structural integrity and fracture mode of minimally prepared resin bonded CAD/CAM crowns. J. Dent. 2010, 38, 16-22. [CrossRef]

34. Craig, J.M.; Sakaguchi, R.L. Craig's Restorative Dental Materials, 12th ed.; Mosby: Maryland Heights, MO, USA, 2006.

35. Yildiz, C.; Vanlığlu, B.A.; Evren, B.; Uludamar, A.; Kulak-Ozkan, Y. Fracture resistance of manually and CAD/CAM manufactured ceramic onlays. J. Prosthodont. 2013, 22, 537-542. [CrossRef]

36. Brosh, T.; Porat, N.; Vardimon, A.D.; Pilo, R. Appropriateness of viscoelastic soft materials as in vitro simulators of the periodontal ligament. J. Oral Rehabil. 2011, 38, 929-939. [CrossRef] [PubMed]

37. Tsitrou, E.A.; Northeast, S.E.; van Noort, R. Evaluation of the marginal fit of three margin designs of resin composite crowns using CAD/CAM. J. Dent. 2007, 35, 68-73. [CrossRef] [PubMed]

38. Stawarczyk, B.; Eichberger, M.; Uhrenbacher, J.; Wimmer, T.; Edelhoff, D.; Schmidlin, P.R. Three-unit reinforced polyetheretherketone composite FDPs: Influence of fabrication method on load-bearing capacity and failure types. Dent. Mater. J. 2015, 34, 7-12. [CrossRef] [PubMed]

39. Burke, F. Maximising the fracture resistance of dentine-bonded all-ceramic crowns. J. Dent. 1999, 27, 169-173. [CrossRef]

40. Kelly, J.R. Clinically relevant approach to failure testing of all-ceramic restorations. J. Prosthet. Dent. 1999, 81, 652-661. [CrossRef]

41. Assif, D.; Marshak, B.L.; Pilo, R. Cuspal flexure associated with amalgam restorations. J. Prosthet. Dent. 1990, 63, $258-262$. [CrossRef]

42. Pest, L.B.; Guidotti, S.; Pietrabissa, R.; Gagliani, M. Stress distribution in a post-restored tooth using the three-dimensional finite element method. J. Oral Rehabil. 2006, 33, 690-697. [CrossRef]

43. Wimmer, T.; Huffmann, A.M.S.; Eichberger, M.; Schmidlin, P.R.; Stawarczyk, B. Two-body wear rate of PEEK, CAD/CAM resin composite and PMMA: Effect of specimen geometries, antagonist materials and test set-up configuration. Dent. Mater. 2016, 32, e127-e136. [CrossRef]

44. Heintze, S.; Albrecht, T.; Cavalleri, A.; Steiner, M. A new method to test the fracture probability of all-ceramic crowns with a dual-axis chewing simulator. Dent. Mater. 2011, 27, e10-e19. [CrossRef]

45. Rosentritt, M.; Behr, M.; Gebhard, R.; Handel, G. Influence of stress simulation parameters on the fracture strength of all-ceramic fixed-partial dentures. Dent. Mater. 2006, 22, 176-182. [CrossRef]

46. Versluis, A.; Versluis-Tantbirojn, D. Filling cavities or restoring teeth? J. Tenn. Dent. Assoc. 2010, 91, 36-42.

47. Kawai, N.; Lin, J.; Youmaru, H.; Shinya, A.; Shinya, A. Effects of three luting agents and cyclic impact loading on shear bond strengths to zirconia with tribochemical treatment. J. Dent. Sci. 2012, 7, 118-124. [CrossRef]

48. Jones, D.W. The Strength and Strengthening Mechanisms of Dental Ceramics. In Dental Ceramics, Proceedings of the First International Symposiums on Ceramics, Held in New Orleans, April 1982; McLean, J.W., Ed.; Quintessence Publishing: Chicago, IL, USA, 1983; pp. 83-141.

49. Van Dijken, J.W. Direct Resin Composite Inlays/Onlays: An 11 Year Follow-Up. J. Dent. 2000, 28, 299-306. [CrossRef]

50. Bindl, A.; Lüthy, H.; Mörmann, W.H. Strength and fracture pattern of monolithic CAD/CAM-generated posterior crowns. Dent. Mater. 2006, 22, 29-36. [CrossRef] [PubMed]

51. Magne, P. Efficient 3D finite element analysis of dental restorative procedures using micro-CT data. Dent. Mater. 2007, 23, 539-548. [CrossRef] [PubMed]

52. Borcic, J.; Braut, A. Finite Element Analysis in Dental Medicine; INTECH Open Access Publisher: London, UK, 2012.

53. Nikkhoo, M.; Lu, M.L.; Chen, W.C.; Fu, C.J.; Niu, C.C.; Lin, Y.H.; Cheng, C.H. Biomechanical Investigation Between Rigid and Semirigid Posterolateral Fixation During Daily Activities: Geometrically Parametric Poroelastic Finite Element Analyses. Front. Bioeng. Biotechnol. 2021, 9, 646079. [CrossRef] [PubMed]

54. Mourya, A.; Nahar, R.; Mishra, S.K.; Chowdhary, R. Stress distribution around different abutments on titanium and CFR-PEEK implant with different prosthetic crowns under parafunctional loading: A 3D FEA study. J. Oral Biol. Craniofacial Res. 2021, 11, 313-320. [CrossRef]

55. Montero, J.; Guadilla, Y.; Flores, J.; Pardal-Peláez, B.; Quispe-López, N.; Gómez-Polo, C.; Dib, A. Patient-Centered Treatment Outcomes with Full-Arch PEEK Rehabilitation Supported on Four Immediate or Conventionally Loaded Implants. A Randomized Clinical Trial. J. Clin. Med. 2021, 10, 4589. [CrossRef]

56. Wang, J.; Wu, P.; Liu, H.-L.; Zhang, L.; Liu, L.-P.; Ma, C.-F.; Chen, J.-H. Polyetheretherketone versus titanium CAD-CAM framework for implant-supported fixed complete dentures: A retrospective study with up to 5-year follow-up. J. Prosthodont. Res. 2021. [CrossRef]

57. Alqurashi, H.; Khurshid, Z.; Syed, A.U.Y.; Habib, S.R.; Rokaya, D.; Zafar, M.S. Polyetherketoneketone (PEKK): An emerging biomaterial for oral implants and dental prostheses. J. Adv. Res. 2020, 28, 87-95. [CrossRef]

58. Zafar, M.S. Prosthodontic Applications of Polymethyl Methacrylate (PMMA): An Update. Polymers 2020, 12, 2299. [CrossRef] [PubMed]

59. Alauddin, M.S.; Baharuddin, A.S.; Mohd Ghazali, M.I. The Modern and Digital Transformation of Oral Health Care: A Mini Review. In Healthcare; Multidisciplinary Digital Publishing Institute: Basel, Switzerland, 2021; Volume 9, p. 118. 